\title{
EMBEDDING AUGMENTED REALITY TECHNOLOGY IN THE EDUCATIONAL LEARNING SYSTEM
}

\section{Fawad Alam}

PhD. Scholar,

Karachi University Business School,

Sindh, Pakistan

Email: fawadalamku@gmail.com

\section{Khurram Iqbal}

Assistant Professor,

College of Computer Sciences \& Information System,

Institute of Business Management,

Sindh, Pakistan

Email: khurramiqbal.nust@gmail.com

\section{Syed Asim Ali}

Assistant Professor,

Department of Computer Science, University of Karachi,

Sindh, Pakistan

Email: asim@uok.edu.pk

\begin{abstract}
Augmented Reality (AR) technology has effective potential that enhances and replaces the old way of learning into a new digitized smart learning environment by converting the school books into a virtual 3D environment, which helps students extracting and absorbing complex concepts in less amount of time. AR is a computer vision-based technology that works by tracking the surrounding using a smartphone camera and then superimposing virtual $3 D$ objects into the real world. The capabilities of AR make classes more engaging, collaborative, and interactive. Studying may not be every student's cup of tea but with the help of a smart learning environment; school lessons can be much more interesting, interactive, and fun to learn. This article aims to brief insight that the interactive AR chemistry application may lead the students to grasp difficult concepts of chemistry more easily entertainingly and engagingly.
\end{abstract}

\section{KEYWORDS}

Augmented Reality (AR), Education, Smart Learning Application, Experimental 
Learning, VAK Learning

\section{INTRODUCTION}

Augmented Reality (AR) an e-learning tool in an education system is a new approach (Liarokapis, 2007; Berryman, 2012; Azuma, 1997; Smuseva \& Rolich, 2018). According to Scrivener (2011) the teacher's main role is " to help to learn to happen" which includes "involving" students in what is going on "by enabling them to work at their speed, by not giving long explanations, by encouraging them to participate, talk, interact, do things. A famous learning style called VAK stands for a visual, auditory, and kinesthetic way of learning. VAK learning style has been used in this paper. VAK is a well-known learning style theory and is accepted globally due to its benefits in all levels of learning and training (Gholami \& Bagheri, 2013).

A person who perceives and learns best from visual images is a visual learner. They depend on the instructor's or facilitator's non-verbal cues such as body language to help with understanding. Sometimes, visual learners favor sitting in front of the classroom. Moreover, they also take descriptive notes over the material presented. While auditory learners, individuals discover information through listening and interpreting information by the means of pitch, accent, and speed. Also, these individuals gain knowledge from reading out loud in the classroom and may not have a full understanding of information written. Individuals are classified as kinesthetic learners, who are best with an active "hands-on" approach or learn by performing experiments. These learners favor interaction with the physical world (Gilakjani, 2012).

Ministry of education governs the education system in Pakistan (Memon, 2007). Each province has its education ministry, which deals and facilitates the educational matters of the province. Currently, the method of education and learning adopted in Pakistan is more conventional with emphasis on verbal educational methods and is not fundamentally compelling (Shamim, 2008). Schools in Pakistan are still using ineffective techniques for delivering lectures, which may cause lack of understandability in students, as some of the concepts are difficult enough that end up making students frustrated and losing interest (Memon, 2009; Shah, 2011).

Learning experience plays an important role in the growth of a student's life cycle and this process should be interactive and interesting so that students feel motivated towards education (Irwansyah et al., 2018). Previous researches are evident that preprimary, primary and secondary students follow the old method of learning. The instructor knows that the learning process should be all about creativity and interaction and their role is to facilitate and create interest in the subject (Rashid \& Mukhtar, 2012). Nowadays most young people have their smartphones. These young people are 
active smartphone users who use these gadgets to access social platforms, play games, and to be in connection with friends and family. Young students are also interacting with smartphones and computers for study e.g. to do the homework, dig information about a subject and playing 3D games, watching animated movies (Deshpande, 2015). We can conclude that 3D graphics attract youngsters, adults as we live in a threedimensional world.

\section{RESEARCH OBJECTIVES}

This research paper studies on the uses of AR in the education system. Introducing and promoting technology in Pakistan for the advancement of education, the use of ARbased applications has a great potential to create a collaborative atmosphere among teachers and students. In Pakistan, education is still working on conventional methods. Technology is getting more advanced and different technologies are available to make educational process of a student easy, like virtual classroom (online learning), podcasts, simulations, virtual reality and augmented reality are available now to serve the education sector. AR is an appropriate tool to replace old school learning techniques with more productive methods having a voice over-explanation, 3D representations, simulation, and animations (Amin \& Govilkar, 2015; Pence, 2010) which satisfies the VAK style of learning.

\section{RESEARCH METHODOLOGY}

AR-Chemistry is an Augmented Reality based educational application build for school students to make learning easy and to capture the difficult concepts in an entertaining way (Bacca et al., 2014 ; Radu ,2014). We especially target difficult and important concepts of chemistry while focusing on the VAK learning style by using Augmented Reality. The following are the difficult concept of chemistry, covered in the ARChemistry App and will be further discussed in this paper.

- Discovery of Electron

- Discovery of Proton

- Rutherford's Gold Foil Experiment

- Radioactive Rays

- Isotope

In the subject of chemistry, often it becomes difficult for the students to understand the experiment or a process, as the diagrams given in the book are not providing enough information to understand the complete concept. Books of chemistry having 2D images should be upgraded to real-world virtual graphics by empowering students with smartphones having an Augmented Reality application (Irwansyah et al., 2018; Bacca et al., 2014). We provide a solution by combining technology with education and developing AR-based applications for schools, which will boost up the learning process of students. Moreover, it will make things easy for the instructor to explain the 
difficult concepts in chemistry and at the same time make it easy for the students to understand and absorb the difficult concepts of chemistry.

AR is commonly capable to overlay computer graphics onto the real world and allows users to see the real world at the same time as virtual imagery attached to reallocation and objects. Furthermore, the AR chemistry application enables students to understand the complex concepts of interestingly and entertainingly. Currently, the teaching methods of schools in Pakistan are based on the syllabus provided by the education board and usually, schools follow books of the same publisher prescribed by the education board. Developing an AR-based application enables each school of the education board to adopt this technology for the betterment of students. Using ARbased educational applications, the teaching and learning process can become more exciting where students can play games and observe experiments by placing the phone in front of a difficult experiment or process in chemistry.

\section{What we used?}

As discussed above the different methods introduced in education to improve teaching style, AR is one of them. AR is based on computer vision uses a camera to generate 3D objects in a real-world environment and lets the user interact with them in various ways including Visual, Auditory, and Kinesthetic. To complete the AR chemistry application, we worked with different other software mentioned below:

- Autodesk Maya has been used to create 3D object (Tang, 2014). The 3D objects created are cathode ray tube, battery, atoms, and plates.

- AR makes it possible to interact with 2D and 3D virtual objects interact with real world environment (Chen \& Tsai, 2012). Unity 3D has been used to develop ARchemistry application.

- AR solutions can be developed by using Unity 3D game engine with Vuforia SDK (Xiao \& Lifeng, 2014; Peng \& Zhai 2017) for the recognition of markers to render objects in AR.

\section{Why use AR?}
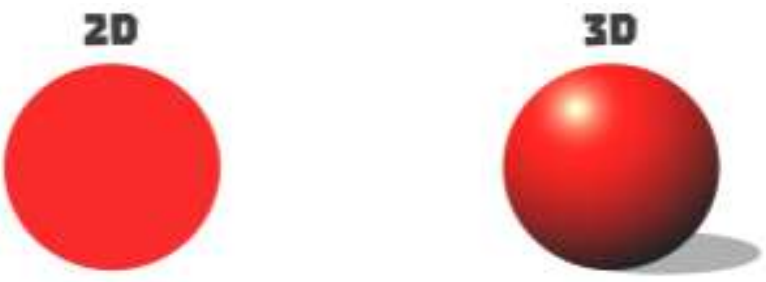

Figure 1. Difference between 2D and 3D 
Figure 1 shows two objects, on the left hand a 2D (dimensional) representation while on the right a 3D (dimensional) representation. The object on the left looks more like a circle and has no attraction while the object on the right is 3D and looks so real and attractive, as it gives a feeling of coming out of the canvas which supports the statement that 3D conveys more details than 2D (Chen \& Tsai, 2012 ; Huk, 2006).

\section{Why People Go with 3D?}

Technology is reaching its new peak day by day and we are very much familiar with 3D animated cartoons, movies, games. All of them are considered to be entertainment stuff. Almost every person enjoys the 3D world of entertainment as it feels more realistic than 2D and it provides more detail and information than 2D like shadows, depth of field, the structure of objects, etc. In the same way, the 3D approach can be implemented for educational purposes which ultimately help in enhancing the learning speed and aids in understanding the difficult concepts easily in a short period. Education systems cannot be restricted to context and pictures and it should be moved towards digitization. The digital world of education is better as it is more interesting, engaging and aids in understanding, memorizing, and learning complex topics. Chemistry is an interesting subject but usually, it becomes difficult for students to understand chemistry or grasp the different concepts of chemistry.

Furthermore, it becomes difficult for the student to understand the atomic structure, molecular structure, and how bonding formed like an ionic bond, covalent bond, coordinate covalent, and polar bonds. Similarly, students struggle in understanding different forms of compounds and different complex experiments. AR chemistry application is a better way to learn and understand chemistry. Teachers can explain difficult concepts easily by projecting the augmented experiments and describe the concept with voice over, which supports all three types of learning styles (Visual, Auditory, and Kinesthetic). For examples:

\section{Discovery of Electron}

J.J. Thomson's experimented with a cathode ray tube and showed that all atoms contain tiny negatively charged subatomic particles or electrons (Thomson, 1897). With the help of an AR chemistry application, it can be transformed into a 3D experiment of cathode ray tube by placing the smartphone over the pictorial representation in the chemistry book of 9th grade which is published by Sindh textbook board as shown in Figure 2. 
Figures 2.1

Experiment of Cathode ray tube

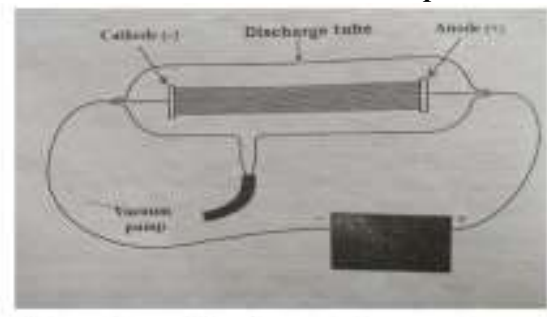

Figure 2,1-a. Discharge tube experiement

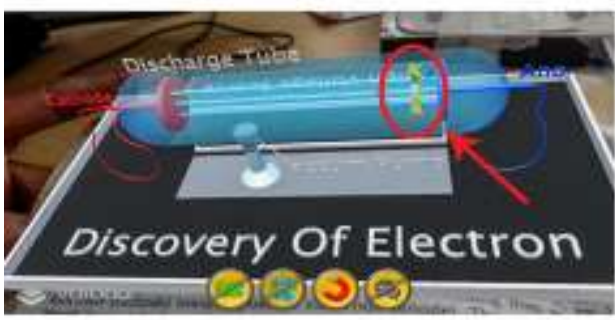

Figure 2.1-c. Material Particle

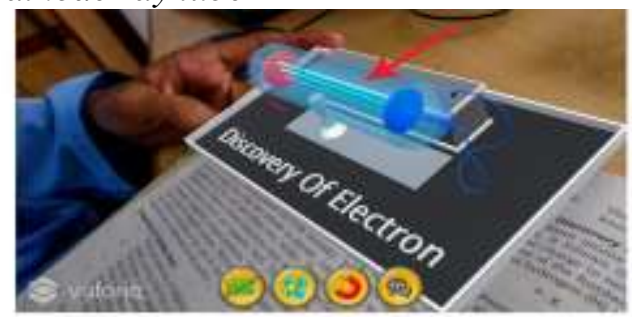

Figure 2,1-b. Rays travel in straight line

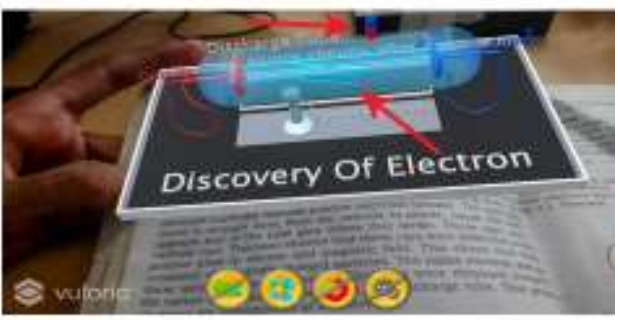

Figure 2.1-d. Deflects in electric field

Figure 2.1-a depicts experiment in the book which will transform into an AR experiment, helps in easy understanding of different properties of cathode rays (Figure 2.1-b) showing that these rays travel in a straight line, (Figure 2.1-c) confirms the property that cathode rays are material particles and (Figure 2.1-d) proves the third property that these rays deflect in the presence of the magnetic field.

\section{Discovery of Proton}

Since the atom is electrically neutral there must be positively charged particles present in the atom to neutralize the negative charges of the electrons. Goldstein has experimented to prove the existence of protons in the atom (Moore et al., 1985).

Figures 2.2

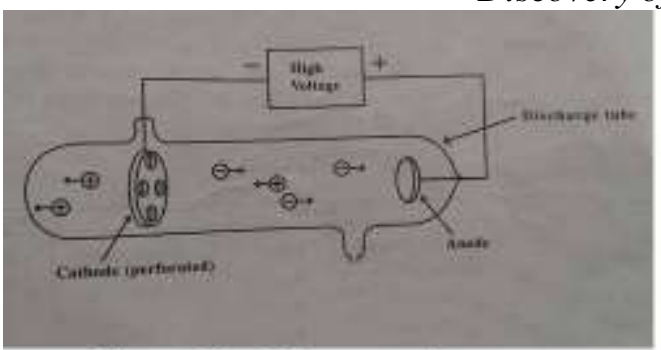

Figure 2.2-a. Discovery of proton

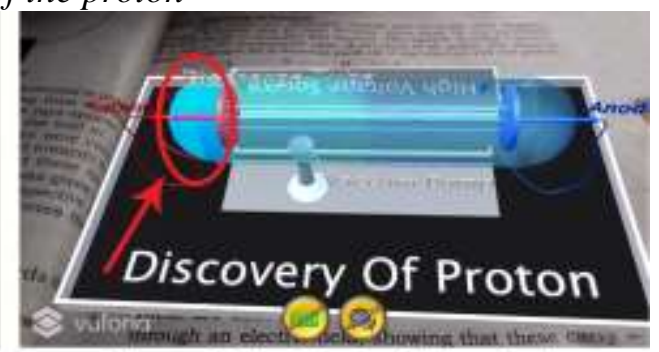

Figure 2.2-b. Glow behind cathode 
(Figures 2.2) is the graphical explanation of experiment "Discovery of Proton" (Figure 2.2-a) shows the $2 \mathrm{D}$ representation where the cathode is perforated and positive charges are going past the cathode and starts glowing when strike with a discharge tube while on the other hand (Figure 2.2-b) provides more concrete visualization and explanation where the positive charges can be seen glowing behind cathode when positive charge strike back to the glass wall of the discharge tube.

\section{Radioactivity}

Experiment of radioactivity (Siegbahn, 2012) is depicted in figure 2.3 by using the AR chemistry application.

\section{Figures 2.3}

Experiment of radioactivity.

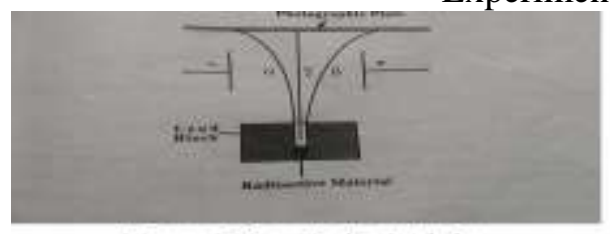

Figure 2,3-a. RadioActivity

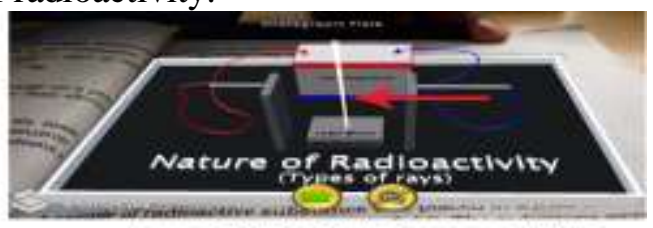

Figure 2,3-b. White battery is OFF

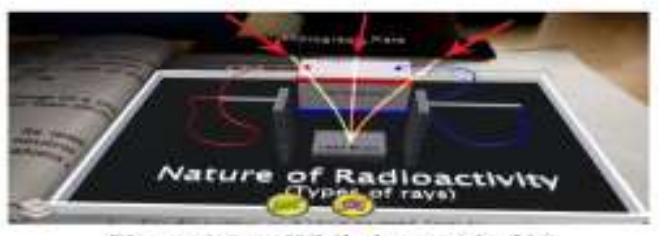

Figure 2,3-c. While battery is $\mathrm{ON}$

(Figure 2.3-a) is used as an image target/marker to augment the 3D experiment over a book while (Figure 2.3-b) shows when the battery is turned OFF the radioactive rays are following a straight path but when the battery is turned ON (Figure 2.3-c) the rays bents toward anode and cathode proves the property of radioactive rays.

\section{Rutherford Gold foil method}

Rutherford experiment (Herron, 1977) is presented in figure 2.4 with the help of AR chemistry application.

Figures 2.4

\section{Experiment of Rutherford}

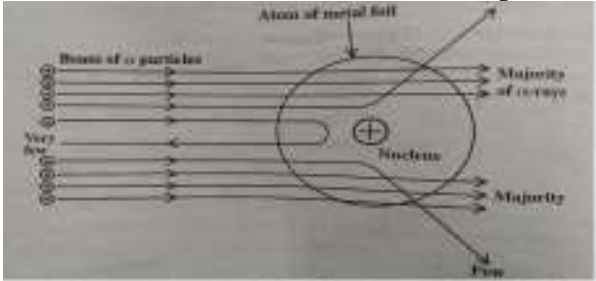

Figure 2.4-a. Rutherford atomic model

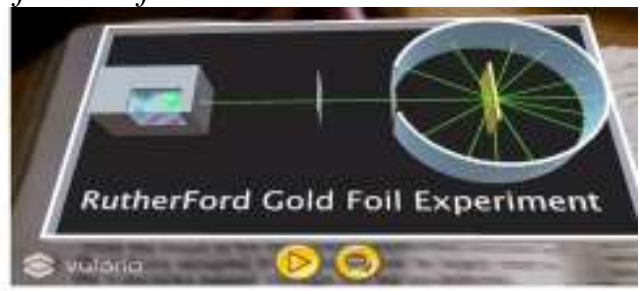

Figure 2,4-b. Deflecting rays 
(Figure 2.4) shows the difference between understanding Rutherford's gold foil experiment in a conventional and modern way where (Figure 2.4-a) which does not provide enough information about the atomic structure of an atom whereas (Figure 2.4-b) portrays enough information of the atomic model as the rays can be seen, some are passing straight, some are deflecting and very few are bouncing back with the help of AR chemistry application.

\section{Isotopes of Hydrogen}

Isotope is defined as elements having the same number of protons but different numbers of neutrons. Hydrogen $(\mathrm{H})$ has three naturally occurring isotopes, sometimes denoted as $1 \mathrm{H}, 2 \mathrm{H}$, and $3 \mathrm{H}$ also called Protium, Deuterium, and Tritium (Genty \& Schott, 1970).

\subsection{Features of the AR-Chemistry Application \\ 2.4.1 Interactive}

The AR chemistry application is interactive as it allows teachers as well students to control the 3D simulation which helps to understand the concepts in a better way. This type of learning follows a kinesthetic way of learning, a VAK learning style.

\subsubsection{D to $3 \mathrm{D}$}

In the existing education system of Pakistan, a blackboard or whiteboard is used by the teachers to teach primary and secondary school children. We used Vuforia API (for image recognition) as a detector for a $2 \mathrm{D}$ image in the book and convert it into a selfcreated 3D object. This plays a significant role in the visualization aspect of VAK learning style and enhancement of the student's learning ability.

\subsubsection{Perspective View}

The perspective view portrays height, width, and depth for a more realistic image or graphic. When the 3D objects or 3D simulation is fixed on the detecting surface it becomes easy to view the complete object from various angles. This also aids in the visual way of learning (one of the VAK learning styles) and makes it easy for students to interact and understand the concept.

\subsubsection{Voice Over}

Voice over helps in grasping concepts, especially in the native language. In AR chemistry application Urdu voiceover has been embedded with the simulation of the experiment, which describes each step of simulation and engaging the student in auditory learning while the student is observing the experiment visually and kinesthetically. Auditory learning is also one of the significant learning styles of VAK. 


\subsubsection{Friendly User Interface}

Ease of use of technology is one of the key features of the technology acceptance model (Davis et al., 1989). If the technology adopted is not easy and convenient to use, then it will be rejected by the targeted audience, and the product is considered to be a fail product. AR chemistry application focuses on the convenient use of the application and enables the user to use and control the functions without any confusion and frustration.

\subsubsection{Cross-Platform Support}

AR chemistry applications can be used in both Android and IOS platforms, which are the most, used mobile operating system all over the world. The application can cater to the needs of both types of smartphone users (those using the android operating system or IOS operating system) to operate the smartphone. The application has been made to fulfill the needs of almost the complete market.

Figures 2.5

Isotopes of Hydrogen

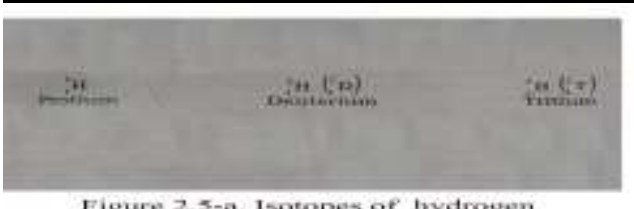

Figure 2.5-a. Isotopes of hydrongen

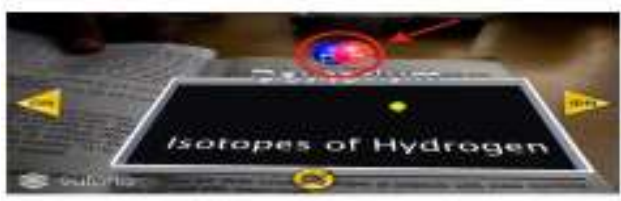

Pigure 2.5-c, Desterium

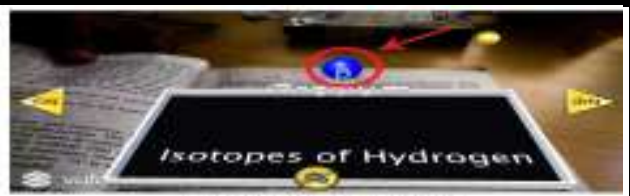

Figure 2.5-b. Protium

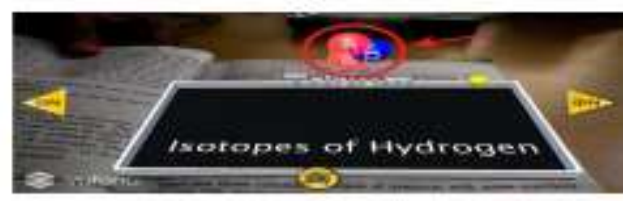

Figure 2.5-d. Tritium

(Figure 2.5-a) shows the chemical formula of three isotopes of hydrogen which does not elaborates enough information to differentiate among them whereas (Figure 2.5-b) gives a complete graphical idea about Protium having 1 proton, 1 electron, and no neutrons, (Figure 2.5-c) showing Deuterium having 1 proton, 1 electron and 1 neutron and (Figure 2.5-d) depicts that Tritium has 1 proton, 1 electron, and 2 neutrons.

\section{DISCUSSION}

\section{How we did it?}

This application is developed by using three main tools described below: 


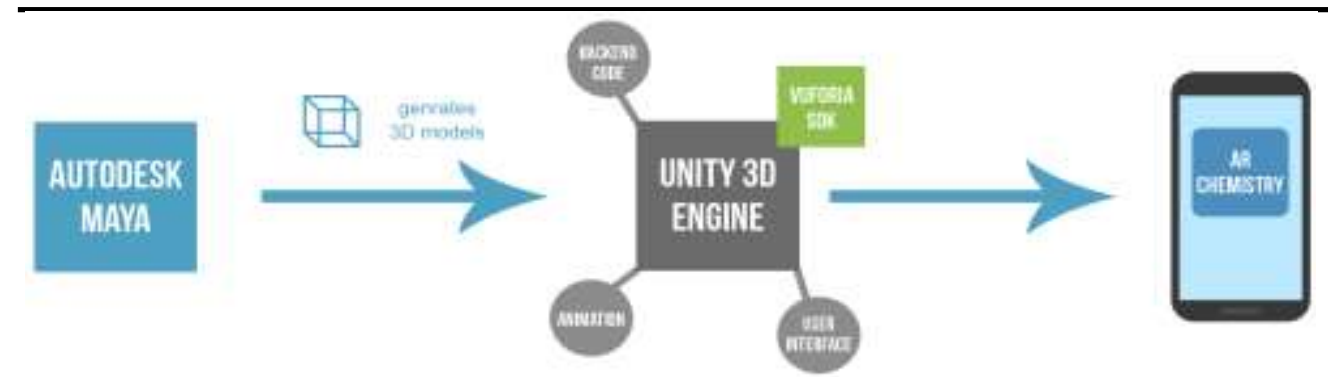

Figure 3, working UML Diagram

\section{D Object Modeling}

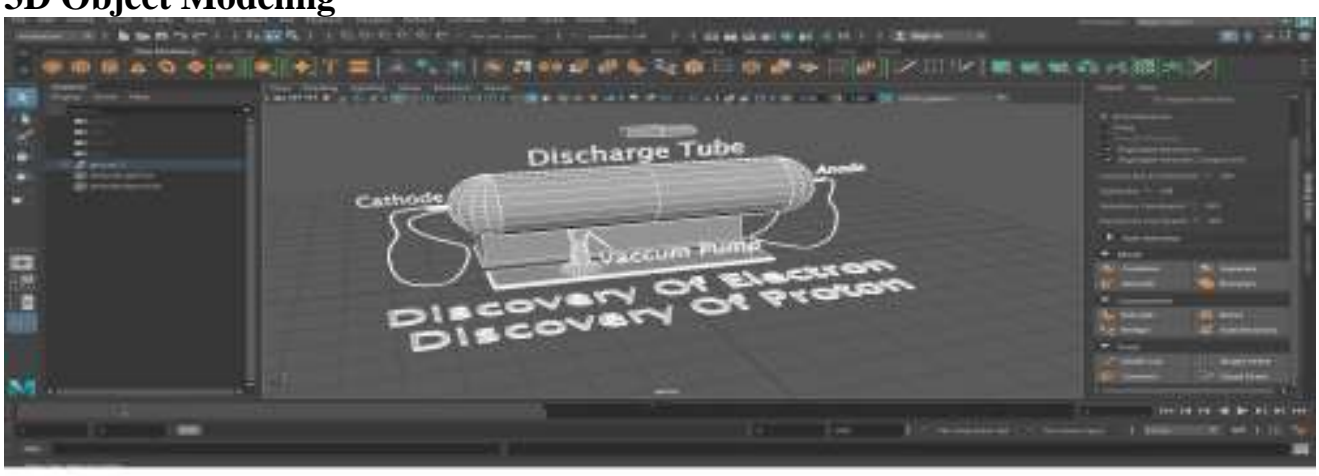

Figure 4. Assets modeling

The main goal was to create 3D content (Figure 4) so that it makes the learning process easy and entertaining, Autodesk Maya helps in creating such attractive graphics (Tang, 2014). The task of modeling the low poly $3 \mathrm{D}$ objects and texturing with attractive design is done by using the best tools of Maya. For 2D art and designing, Illustration tools were used.

\section{Integration in Gaming Engine}

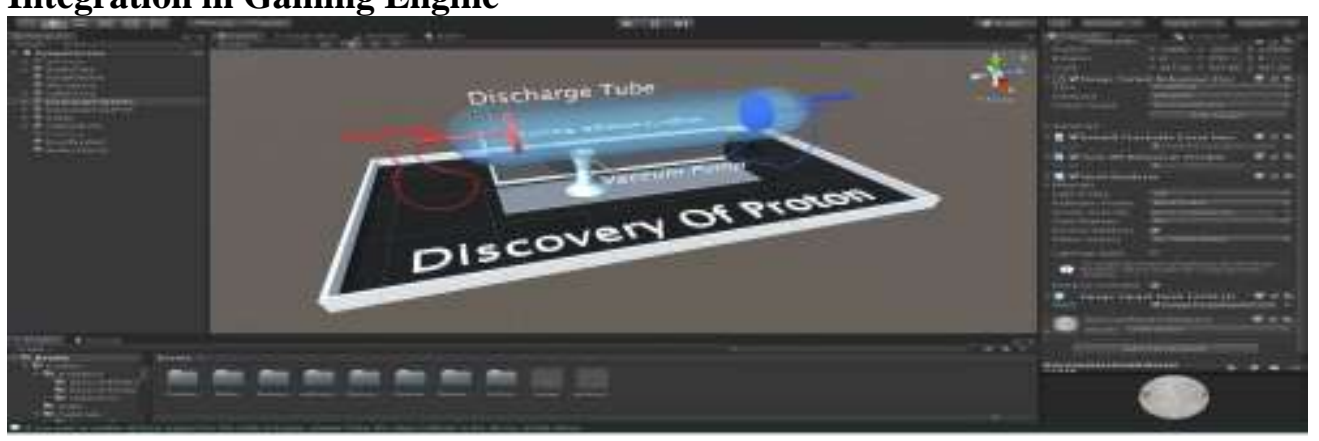

Figure 5. Integration in gaming engine 
The end product is the result of integrating 3D objects (Figure 5) in Unity so that they can be made interactive. The work was divided into 3 main sections. User interface building, animation of objects, and most importantly backend programming to make it controllable.

\section{Animation}

Still and motionless objects make us bored after a while. On the other hand, objects in motion capture our attention (Daly et al., 2016). Following this theory, 3D experiments have been animated to make them more attractive and portray better understandability among the audience. Unity game development kit provides vast animation tools and works by placing the keys in the animation timeline and recording the animation on these timelines. Every single animation in the application is created using the animation component in Unity. Moreover, it creates smooth and realistic animation which helps in achieving good results.

\section{Backend Programming}

It is the main part of the AR chemistry application which enables the audience to perform certain functions by interacting with the user interface. Unity provides the feature of scripting which allows writing functions as per requirements, for backend coding Microsoft C\# has been used. C\# is an Object-Oriented Programing language that makes it easy to write functions (Hejlsberg et al., 2003) . The community of C\# is also very strong and $\mathrm{C \#}$ is a very mature language that provides developer full control over functions in Unity. Here is a simple backend function in C\# which performs the wheel paddle animation in Discharge Tube Experiment when the user clicks on the button:

Public void OnRotateClick() \{

if ( startBool $==$ true)

$\{$ WheelAnimAttach.gameObject.GetComponent $<$ Animator $>($ ).enabled $=$ true;

WheelAnimAttach.GetComponent<Animation>().Play("paddleRotate");

Elseif (startBool==false)

$\{$ WheelAnimAttach.gameObject.GetComponent $<$ Animator $>($ ).enabled $=$ false;

WheelAnimAttach.GetComponent<Animation>().Stop("paddleRotate"); \}

\section{CONCLUSION}

Augmented Reality (AR) based applications are not only facilitating the teachers but also to the students to enhance their understanding of the topic under investigation and increase their speed of learning. This approach implies that AR-based learning media on the android system as well as on IOS platforms has the potential to be applied to the learning of chemistry, especially on the topics that are difficult for teachers to elaborate and for students to understand. This application helps to discover knowledge and information in attractive and easy way for learners. This application will also 
increase the overall class collaboration among the students, and satisfies all the three styles of learning styles called VAK style.

\section{RECOMMENDATIONS}

A few suggestions need to be implemented in our education system:

It is recommended that the augmented reality-based applications must be made mandatory to teach science subjects and complex topics of other domains by the government of Pakistan. This is due to the reason that it will help both instructors and students to convey and understand the concepts effectively and interactively.

Instructors should adopt augmented reality-based applications while delivering the lecture to their students. In this manner, the learning ability of the students will be enhanced. Last but not least, augmented reality-based applications can play a vital role in the student's learning process so that students feel motivated towards education.

\section{REFERENCES}

Amin, D., \& Govilkar, S. (2015). Comparative study of augmented reality SDKs. International Journal on Computational Science \& Applications, 5(1), 11-26. https://doi.org/10.5121/ijcsa.2015.5102

Azuma, R.T. (1997). A survey of augmented reality. Presence: Teleoperators and Virtual Environments, 6 (4), 355-385 https://doi.org/10.1162/pres.1997.6.4.355

Bacca Acosta, J. L., Baldiris Navarro, S. M., Fabregat Gesa, R., \& Graf, S. (2014). Augmented reality trends in education: A systematic review of research and applications. Journal of Educational Technology and Society, 17( 4), 133-149.

Berryman, D.R. (2012). Augmented reality: A review. Medical Reference Services Quarterly, 31(2), 212-218. https://doi.org/10.1080/02763869.2012.670604

Chen, C. M., \& Tsai, Y. N. (2012). Interactive augmented reality system for enhancing library instruction in elementary schools. Computers \& Education, 59(2), 638-652. https://doi.org/10.1016/j.compedu.2012.03.001

Daly, C. J., Bulloch, J. M., Ma, M., \& Aidulis, D. (2016). A comparison of animated versus static images in an instructional multimedia presentation. Advances in physiology education, 40(2), 201-205. https://doi.org/10.1152/advan.00053.2015

Davis, F. D., Bagozzi, R. P., \& Warshaw, P. R. (1989). User acceptance of computer technology: A comparison of two theoretical models. Management science, 35(8), 982-1003. https://doi.org/10.1287/mnsc.35.8.982

Deshpande, A. (2015). Mobile addiction and associated factors amongst youth. Indian Journal of Mental Health, 2(3), 244-248. https://doi.org/10.30877/ijmh.2.3.2015.244-248

Genty, C., \& Schott, R. (1970). Quantitative analysis for the isotopes of hydrogen-H2, HD, HT, 
D2, DT, and T2-by gas chromatography. Analytical Chemistry, 42(1), 7-11. https://doi.org/10.1021/ac60283a039

Gholami, S., \& Bagheri, M. S. (2013). Relationship between VAK learning styles and problem solving styles regarding gender and students' fields of study. Journal of Language Teaching and Research, 4(4), 700-706. https://doi.org/10.4304/jltr.4.4.700-706

Hejlsberg, A., Wiltamuth, S., \& Golde, P. (2003). C\# language specification. Addison-Wesley Longman Publishing Co., Inc.

Herron, J. D. (1977). Rutherford and the nuclear atom. Journal of Chemical Education, 54(8), 499. https://doi.org/10.1021/ed054p499.1

Huk, T. (2006). Who benefits from learning with 3D models? The case of spatial ability. Journal of Computer Assisted Learning, 22(6), 392-404. https://doi.org/10.1111/j.1365-2729.2006.00180.x

Irwansyah, F. S., Yusuf, Y. M., Farida, I., \& Ramdhani, M. A. (2018, January). Augmented reality (AR) technology on the android operating system in chemistry learning. In IOP conference series: Materials science and engineering (Vol. 288, No. 1, p. 012068). IOP Publishing. https://doi.org/10.1088/1757-899x/288/1/012068

Liarokapis, F. (2007). An augmented reality interface for visualizing and interacting with virtual content. Virtual Reality, 11(1), 23-43. https://doi.org/10.1007/s10055-006-0055-1

Memon, G. R. (2007). Education in Pakistan: The key issues, problems and the new challenges. Journal of Management and Social Sciences, 3(1), 47-55.

Memon, I. K. (2009). Anatomy education faces challenges in Pakistan. Anatomical Sciences Education, 2(4), 193-194. https://doi.org/10.1002/ase.77

Moore, C. E., Jaselskis, B., \& von Smolinski, A. (1985). The proton. Journal of Chemical Education, 62(10), 859.

Pence, H. E. (2010). Smartphones, smart objects, and augmented reality. The Reference Librarian, 52(1-2), 136-145. https://doi.org/10.1080/02763877.2011.528281

Peng, F., \& Zhai, J. (2017, June). A mobile augmented reality system for exhibition hall based on Vuforia. In 2017 2nd International Conference on Image, Vision and Computing (ICIVC) (pp. 1049-1052). IEEE. https://doi.org/10.1109/icivc.2017.7984714

Radu, I. (2014). Augmented reality in education: A meta-review and cross-media analysis. Personal and Ubiquitous Computing, 18(6), 1533-1543. https://doi.org/10.1007/s00779-013-0747-y

Rashid, K., \& Mukhtar, S. (2012). Education in Pakistan: Problems and their solutions. International Journal of Academic Research in Business and Social Sciences, 2(11), 332.

Scrivener, J. (2011). Learning teaching: The essential guide to english language teaching, Macmillan Education. 
Shah, S. M. (2011). Decentralization in Education in Pakistan: Performance and Problems of the Principles of Higher Secondary and Secondary Schools, Pakistan Journal of Education, 28(1). https://doi.org/10.30971/pje.v28i1.131

Shamim, F. (2008). Trends, issues and challenges in English language education in Pakistan. Asia Pacific Journal of Education, 28(3), 235-249. https://doi.org/10.1080/02188790802267324

Siegbahn, K. (Ed.). (2012). Alpha-, beta-and gamma-ray spectroscopy. Elsevier. https://doi.org/10.1016/c2009-0-07296-1

Smuseva, D. A., \& Rolich, A. Y. (2018). Research and software development using AR technology. Journal of Physics: Conference Series (Vol. 1050, No. 1, p. 012080). IOP Publishing. https://doi.org/10.1088/1742-6596/1050/1/012080

Tang, M. (2014). Parametric building design using Autodesk Maya. Routledge. https://doi.org/10.4324/9781315819877

Thomson, J. J. (1897). Cathode rays. Phil. Mag. Ser. 5, 44, 293-316.

Xiao, C., \& Lifeng, Z. (2014, June). Implementation of mobile augmented reality based on Vuforia and Rawajali. In 2014 IEEE 5th International Conference on Software Engineering and Service Science (pp. 912-915). IEEE.

https://doi.org/10.1109/icsess.2014.6933713 